\title{
Estrategias de gestión para el desarrollo del Proyecto de Ética, Estética y Ciudadanía. Estudio comparativo de los colegios dirección tres de la Dirección Regional de Occidente en el curso lectivo 2013
}

\author{
Management Strategy for an Ethics, Esthetics and Citizenship Program: A Comparative Study \\ of High Schools in Regional Western School District 3 during the 2013 School Year
}

Recibido 30 abril 2014 • Aceptado 18 junio 2014 • Corregido 23 junio 2014

\author{
Denier Ángel Benavides Soto' \\ Instituto San Juan Bosco \\ San José, Costa Rica \\ dernier90@hotmail.com \\ Andreína Murillo Vargas ${ }^{2}$ \\ Ministerio de Educación Pública \\ San José, Costa Rica \\ andremv28@gmail.com \\ María Elisa Navarra Carranza ${ }^{3}$ \\ Ministerio de Educación Pública \\ San José, Costa Rica \\ maria3086@gmail.com
Gerardo Alonso Porras Berrocal ${ }^{4}$
Ministerio de Educación Pública
San José, Costa Rica
gapb2106@gmail.com

$1 \quad$ Licenciado en Ciencias de la Educación con énfasis en Administración de la Educación de la Universidad de Costa Rica y Bachiller en la Enseñanza de los Estudios Sociales de la Universidad de Costa Rica. Ha laborado como docente del Ministerio de Educación Pública en el Liceo Chachagua de Peñas Blancas, en San Ramón de Alajuela. Actualmente labora como docente del Instituto San Juan Bosco.

2 Licenciada en Ciencias de la Educación con énfasis en Administración de la Educación de la Universidad de Costa Rica y Bachiller en la Enseñanza de los Estudios Sociales de la Universidad de Costa Rica. Actualmente labora como docente en el Colegio Técnico Profesional La Tigra del Ministerio de Educación Pública, en San Carlos de Alajuela.

3 Licenciado en Ciencias de la Educación con énfasis en Administración de la Educación de la Universidad de Costa Rica y Bachiller en la Enseñanza de los Estudios Sociales de la Universidad de Costa Rica. Actualmente labora como docente del Ministerio de Educación Pública en el Liceo Los Ángeles en el Porvenir, Nandayure, Guanacaste.

4 Licenciado en Ciencias de la Educación con énfasis en Administración de la Educación de la Universidad de Costa Rica y Bachiller en la Enseñanza de los Estudios Sociales de la Universidad de Costa Rica. Actualmente labora como docente en el Colegio Técnico Profesional de Santa Eulalia, en Atenas de Alajuela y en el Colegio Nacional Virtual Marco Tulio Salazar, sede Liceo San José, en Barrio México de San José, ambos del Ministerio de Educación Pública. 


\section{Criss Dayana Vargas Rodríguez ${ }^{5}$ Ministerio de Educación Pública San José, Costa Rica crissvrgs@hotmail.com}

Resumen. El presente artículo, es un extracto de la investigación que trata sobre las estrategias de gestión para el desarrollo del Proyecto de Ética, Estética y Ciudadanía en los colegios dirección 3 de la Dirección Regional de Occidente en el curso lectivo 2013, por lo que se toma en cuenta como objeto de estudio las instituciones educativas: Instituto Julio Acosta García, Colegio Bilingüe de Palmares y Colegio de Naranjo, instituciones de dependencia pública, con estructura curricular de III ciclo y Diversificado Académicos Diurnos. Para realizar el estudio, se empleó un enfoque de carácter descriptivo, con uso de técnicas metodológicas de tipo mixta o multimodal, dado que incorpora metodología cualitativa y cuantitativa. Incluyó además entrevistas a estudiantes pertenecientes al Comité Ejecutivo Estudiantil y a administradores de la educación de cada una de las instituciones anteriormente mencionadas; así como encuestas dirigidas a docentes. En términos generales, la investigación comprueba que en lo que respecta a la gestión de proyectos como el caso de Ética, Estética y Ciudadanía, aún hace falta una verdadera incorporación de todas las estrategias necesarias para su desarrollo integral, si bien algunas actividades son gestionadas de forma aceptable a criterio del cuerpo docente, administradores de la educación y estudiantes, la gestión del proyecto representa una debilidad. Por lo tanto es necesario potenciar una mejor planificación, organización, dirección, coordinación y evaluación de las actividades para alcanzar mejores resultados.

Palabras clave. Gestión educativa; administración de la educación; planificación; dirección; coordinación.

Abstract. This article is an excerpt from a research project on developing an ethics, esthetics and citizenship management project in high schools from Western Regional Office 3, during the 2013 schoolyear. Participating high schools include Julio Acosta García Institute, Palmares Bilingual High School and Naranjo High School, all public high schools. The aforementioned institutions are day schools covering a Cycle III Diversified curriculum. The study is descriptive and based on combined or multimodal methodological techniques involving both qualitative and quantitative methodologies. The author interviewed students from the Executive Student Body Committee and school administrators as well as teachers who were asked to participate in a survey. The research concludes that more strategies must be put in place to fully develop an Ethics, Esthetics and Citizenship Program. Based on the criteria of the faculty, administrators and students, project management is a weakness and requires better planning, leadership, organization and assessment of activities to ensure a successful output.

Keywords. Education management, planning, leadership, coordination.

$5 \quad$ Licenciada en Ciencias de la Educación con énfasis en Administración de la Educación de la Universidad de Costa Rica y Bachiller en la Enseñanza de los Estudios Sociales de la Universidad de Costa Rica. Ha laborado como docente del Ministerio de Educación Pública en el Liceo de Alfaro Ruiz en Zarcero de Alajuela. Actualmente labora como docente en el programa de Educación para Jóvenes y Adultos en la Escuela Otilio Ulate Blanco del Ministerio de Educación Pública en Zarcero. 
Rev. Gestión de la Educación, Vol. 4, № 2, [31-59], ISSN: 2215-2288, julio-diciembre, 2014

DOI: http://dx.doi.org/10.15517/rge.v4i2.15144

URL: http://revistas.ucr.ac.cr/index.php/gestedu

\section{INTRODUCCIÓN}

En el análisis de la gestión del Proyecto de Ética, Estética y Ciudadanía, es trascendental el estudio de la implementación de los programas educativos y las políticas innovadoras, aspectos que requieren de una administración activa, colaborativa y evaluadora de las medidas establecidas por los entes educativos. En cuanto a la gestión de la educación, los administradores han asumido una tarea importante como lo es la dirección de los centros educativos, una función que implica un proceso que no solo se basa en controlar y planificar, sino en tomar decisiones bajo la autoridad y el orden que le faculta su posición de directivo, esto para dirigir la educación hacia los mejores niveles de calidad. Es así que, Garbanzo y Orozco (2007, p. 102) señalan que "un reto de la administración de la educación es articular los diferentes subsistemas que intervienen en la gestión educativa, de manera que los resultados se obtengan con eficiencia, según los intereses sociales". Es decir, los administradores de la educación tienen la tarea de articular toda la estructura educativa hacia el logro de los resultados planteados, y que estos se logren con calidad y con la participación de toda la comunidad educativa.

Con el Proyecto se persigue una transformación de los procesos educativos actuales, es así que el Ministerio de Educación Pública (MEP, 2009) presentó su propuesta pedagógicametodológica desde un enfoque constructivista, humanista y racionalista, basado en talleres, con el propósito de revertir la deserción estudiantil en el Tercer Ciclo y la Educación Diversificada y atender las nuevas demandas educativas. Por ello, es importante destacar la función mediadora de los docentes en el desarrollo y aplicación de estas nuevas políticas curriculares y de la dirección educativa en los distintos elementos de la administración, a través de estrategias metodológicas con las cuales se hace la ejecución de estos proyectos.

Sin embargo, el Programa del Estado de la Nación (2011, p. 147), asegura que este desempeño directivo ha presentado dificultades respecto a la aplicación "(...) de procesos de evaluación y seguimiento de las actividades y, por tanto, de su impacto sobre el docente y el centro educativo", por lo cual, es trascendental que se desarrollen adecuados procesos de gestión, a través de los cuales se haga un cumplimiento efectivo de los objetivos reales del Proyecto. De esta forma, se hace presente la necesidad de gestionar de tal manera que permita identificar el manejo de los nuevos programas de estudio en el proceso de enseñanza y aprendizaje, actividad que ha sido poco investigada producto de su reciente aplicación en el aula.

De ahí, que se planteó la siguiente interrogante de investigación para este estudio, de la cual se desprenden el objetivo general y específicos referidos.

¿Cuál es la gestión del centro educativo en el proceso de planificación, organización, dirección, coordinación y evaluación del Proyecto Ética, Estética y Ciudadanía en los colegios dirección 3 de la Dirección Regional de Occidente? 


\section{Objetivo general}

- Analizar las estrategias de gestión para el desarrollo del Proyecto de Ética, Estética y Ciudadanía en los colegios dirección 3 de la Dirección Regional de Occidente.

\section{Objetivos específicos}

- Identificar las estrategias de planificación para la gestión del Proyecto de Ética, Estética y Ciudadanía.

- Reconocer las estrategias de organización para la gestión del Proyecto de Ética, Estética y Ciudadanía.

- Identificar las estrategias de dirección para la gestión del Proyecto de Ética, Estética y Ciudadanía.

- Distinguir la ejecución de las estrategias de coordinación para la gestión del Proyecto de Ética, Estética y Ciudadanía.

- Reconocer las herramientas de evaluación para la gestión del Proyecto de Ética, Estética y Ciudadanía.

- Determinar los aspectos por mejorar y los elementos positivos de la gestión del proyecto mediante la técnica FODA.

Las instituciones participantes en el estudio fueron escogidas debido a que presentan aspectos en común, tales como su ubicación en la Dirección Regional de Occidente y la categoría de dirección tres, lo cual indica que son las instituciones que presentan mayor población estudiantil y personal docente, lo que genera los insumos necesarios para la aplicabilidad de los instrumentos y el posterior análisis de los resultados obtenidos para llevar a cabo la comparación de los datos. Estas instituciones son: Instituto Julio Acosta García, Colegio Bilingüe de Palmares y el Colegio de Naranjo.

\section{Antecedentes}

Para el proceso de la información se realizó una compendio de diferentes investigaciones en las bibliotecas de la Universidad de Costa Rica, como lo es la biblioteca Luis Demetrio Tinoco (Sede Central) y, principalmente, en la Arturo Agüero Chaves (Sede de Occidente). Además, se hizo una revisión en la base de datos del Sistema de Bibliotecas, Documentación e Información (SIBDI) de la Universidad de Costa Rica. Las investigaciones que se tomaron en cuenta para este trabajo son de nivel nacional e internacional. Dentro de las primeras, se investigaron seis tesis relacionadas con gestión y educación; en cuanto a las segundas, se tomó en cuenta un trabajo realizado en Baja California, bajo de la misma temática.

En la bibliografía nacional se consultó a Mora (1998) con el trabajo denominado Curso de capacitación para el mejoramiento del proceso de supervisión y evaluación curricular de la Unidad

Licencia Creative Commons 
Rev. Gestión de la Educación, Vol. 4, N² 2, [31-59], ISSN: 2215-2288, julio-diciembre, 2014

DOI:http://dx.doi.org/10.15517/rge.v4i2.15144

URL: http://revistas.ucr.ac.cr/index.php/gestedu

Pedagógica Dr. Rafael Ángel Calderón Guardia. En este trabajo se presenta la importancia del proceso de evaluación y supervisión del currículo, así como de otras actividades administrativas dentro del quehacer de las labores que los profesionales encargados de la administración de la educación tiene como función en los centros de enseñanza.

Además, establece la distinción entre la evaluación y la supervisión en la tarea educativa, así como la clarificación de las funciones que los encargados de la administración deben ejercer como supervisor, una de las actividades por analizar en la investigación que se desarrolla junto a los otros elementos y aspectos por mejorar de la gestión del director o directora. También, se sugiere el uso de una muestra similar para la obtención de datos, mediante instrumentos mixtos y cualitativos como cuestionarios, listas de cotejo y hojas de registro.

Por otra parte, se investigó el trabajo de Chacón (2002), titulado El director como organizador y gestor de los procesos educativos, en el cual se señala que la administración, organización institucional, los propósitos, los elementos, son aspectos que abarca el término gestión, por lo que distintos estudios se preocupan por describir y analizar estos procesos para mejorar la administración de la educación. En tanto que, la gestión, se convierte nuevamente, en un aspecto necesario a tener en consideración para el desarrollo de una investigación que pretende analizar las estrategias de gestión en el desarrollo del Proyecto de Ética, Estética y Ciudadanía.

Aunado a ello, propone el uso de la observación participante, notas de campo, entrevistas dirigidas, entrevistas grabadas y las historias profesionales. Al respecto, explica que cuanta más variedad de fuentes mayor cantidad de información; no obstante, la variedad no significa calidad, por tanto que, siempre es necesario validar estos instrumentos para la depuración de datos. Lo importante es valorar cada uno de los instrumentos que se presentan para al abordaje de la temática y determinar el o los más oportunos para la investigación.

Por otra parte, se tomó en cuenta el trabajo de Solera (2011), denominado Análisis de los procesos de gestión del proyecto extracurricular Banda Instrumental Escuela Riojalandia, el cual refiere que, el analizar los procesos de gestión de proyectos extracurriculares y su incidencia en el entorno educativo, constituye un aspecto importante para la definición de propuestas metodológicas de mejora. Este aspecto contribuye esclarecer un mejor entendimiento de cuáles lineamientos pueden seguirse y preferiblemente mejorarse en la labor de la gestión de las y los administradores de la educación.

También se consultó el trabajo de Mora (2011), Análisis de la labor del Coordinador Académico en la gestión del currículo en las organizaciones educativas de secundaria públicas de la direcciones regionales de San Joséy Desamparados, el cual distingue las funciones ejercidas entre los coordinadores académicos y los encargados de la administración de la educación, puesto que se presenta el detalle de las actividades que cada puesto cumple, así como de su complemento para el desarrollo de los procesos de gestión en las instituciones educativas, en el control y evaluación de planes y estrategias, y la promoción de capacitaciones hacia el personal docente. Con ello, se presenta lo fundamental de la labor de los administradores de la educación en la gestión de proyectos y políticas educativas, así como de la importancia del trabajo que realizan las otras personas para el desarrollo de estos procesos. 
Y por último, otro de los trabajos consultados fue el de Naranjo (2012), denominado Aporte del Programa Ética, Estética y Ciudadanía en el Fortalecimiento de los derechos Humanos de la Adolescencia de Naranjo, que trata específicamente el impacto del Proyecto de Ética, Estética y Ciudadanía, y el aporte que este da en cuanto a los procesos educativos, donde se propone la delimitación de población en estudiantes de secundaria y de un colegio de la misma modalidad. Respecto a lo anterior, se vislumbra el aporte del programa para el aprendizaje de los estudiantes y los resultados que el mismo sigue, aspectos que pueden ayudar a entender mejor la gestión de los encargados de la administración de la educación.

Dentro de los trabajos investigados realizados por entes internacionales, se encuentra el trabajo de García (2009) denominado La gestión escolar como medio para lograr la calidad en instituciones públicas de educación primaria en Ensenada, Baja California, el cual pone de manifiesto que, en la gestión, debe existir la planificación y organización de las tareas por realizar, de manera que se presente un mayor aprovechamiento del tiempo y recursos de la institución. Así, se propone la elaboración de un estudio centrado en lo particular como método para el abordaje de la gestión educativa, aspecto que apoya el estudio de casos como el de la investigación que aquí se desarrolla acerca de las estrategias de gestión respecto al desarrollo del Proyecto de Ética, Estética y Ciudadanía. Además, se sugiere la utilización de instrumentos cualitativos y cuantitativos para caracterizar las actividades del gestor y reconocer las necesidades de formación de los mismos.

\section{MARCO REFERENCIAL}

Para una mejor comprensión de las estrategias de gestión en el desarrollo del Proyecto de Ética, Estética y Ciudadanía, es necesario conocer el eje central que guía este Proyecto, lo cual sugiere reflexionar y analizar el ¿para qué se educa en Costa Rica? De este modo se tendrá una mejor visión de los fundamentos conceptuales en los que se basa el Proyecto, sus objetivos, estrategias y recursos necesarios para su implementación adecuada, su inclusión dentro de los fines de la educación, así como del cumplimiento de sus principales propósitos.

El Proyecto de Ética, Estética y Ciudadanía (PEEC) se pone en práctica en el 2009 y nace cuando se evidencia que los conocimientos valores y actitudes éticas y estéticas formaban parte de la formación integral. Se evidencia en las asignaturas de Artes Plásticas, Educación Musical, Educación Cívica, Educación Física, Artes Industriales y Educación para el Hogar, dentro de esas asignaturas se definen los nuevos programas y bajo la supervisión de los más altos mandos a nivel educativo.

Este proyecto se centró en posturas curriculares y pedagógicas que intentaron responder a los propósitos educativos. Como lo indica MEP (2009, p. 13), "(...) la educación es para la vida y la convivencia”. Demandó ciertas necesidades, la definición clara de los conceptos así como la modificación de los programas, capacitación del profesorado y elaboración de materiales didácticos para una mejor ejecución.

Dentro de los enfoques en que se encuentra inmerso el proyecto están el humanista, racionalista y constructivista; por ende, busca cultivar valores y cultivar una capacidad racional que permite construir

Licencia Creative Commons 
Rev. Gestión de la Educación, Vol. 4, N² 2, [31-59], ISSN: 2215-2288, julio-diciembre, 2014

DOI:http://dx.doi.org/10.15517/rge.v4i2.15144

URL: http://revistas.ucr.ac.cr/index.php/gestedu

y reconstruir conocimiento a partir de la captación objetiva de la realidad y que además, el estudiante construya su propio conocimiento a partir de las experiencias vividas y construidas por sí mismo, con el fin de que tenga un aprendizaje continuo y progresivo.

La propuesta metodológica del proyecto busca concretarse con la realización de proyectos y talleres que respondieran a las estrategias colectivas de aprendizaje, donde docentes y estudiantes, como lo indica el MEP (2009, p. 26), "(...) interactúan como corresponsables del proceso de enseñanza y aprendizaje, pero la participación de cada uno y cada una posee sus propias responsabilidades, alcances y límites"; es decir, que se realice de manera integral en conjunto docentes y estudiantes.

Lo anterior, concierne al Proyecto de Ética, Estética y Ciudadanía el cual responde a las políticas educativas diseñadas por el Ministerio de Educación Pública de Costa Rica. Este Proyecto es central en el desarrollo de esta investigación, por cuanto permite analizar las estrategias de gestión que se realizan alrededor de los talleres y actividades institucionales en el escenario de los centros educativos de secundaria y las funciones que cumplen los distintos actores para la consecución efectiva de los procesos educativos.

\section{MARCO TEÓRICO}

En el siguiente apartado, se presentan los principales fundamentos teóricos relacionados con las estrategias de gestión para el desarrollo del Proyecto de Ética, Estética y Ciudadanía. Para ello, se establecen las definiciones de diversos autores en relación con las principales características de cada concepto y la relevancia de estos dentro del proceso administrativo y la investigación.

\section{Conceptualización de la Administración de la Educación}

Un aspecto central en el correcto desarrollo de las organizaciones educativas, corresponde a la labor que se ejerce desde la administración de la educación. Ante ello, la administración de la educación, como bien dice Vargas (2008, p. 2), es una actividad práctica que "(...) supone una deliberación y una toma de decisiones responsable, que permita a los profesores de la escuela asumir un papel activo en la construcción de una comunidad educada y capaz de establecer un orden dinámico y democrático". Para el autor, esta disciplina constituye una labor de dirección responsable que permita a los demás actores del proceso educativo realizar las acciones más acordes con la realidad de la institución.

Por lo que, la administración de la educación se entiende como una disciplina compleja con la capacidad de administrar el proceso educativo de una forma sostenible con los intereses y necesidades del entorno social y humano, mediante la gestión científica de los componentes que intervienen en su desarrollo y actuar en la sociedad. La administración de la educación, comprende así una actividad que complementa diferentes áreas, en integración de sus especificidades, para el logro de la eficacia y la eficiencia administrativa y educativa en la aplicación de los proyectos educativos. 


\section{Conceptualización de gestión educativa}

La gestión educativa es un conjunto de procesos en los que se presentan la toma de decisionesyla puesta en práctica de acciones diversas que se dirigen al cumplimiento pedagógico, ello según Botero (2009). Por tanto, es indispensable la gestión de los centros educativos para el buen desarrollo de los proyectos, planes anuales institucionales y el desarrollo de los programas de estudio y de todos aquellos proyectos que van en pro de la mejora del proceso educativo, debido a que a partir de la toma de decisiones adecuadas y acciones específicas se convierten en los medios para alcanzar las metas.

Ante los retos, hay personas y organizaciones que son capaces de distinguir las oportunidades mientras que otras solo perciben las amenazas; es así que, según Ricart y Rodríguez (2004), la integración de los sistemas de gestión, permiten identificar una serie de ventajas directas, definidas como aquellas que las empresas suelen percibir con mayor facilidad y que frecuentan impulsar el proceso de integración de los sistemas de gestión, donde se plantea un mejor aprovechamiento de los recursos de las organizaciones, mientras que las ventajas indirectas son menos tangibles pero suelen tener una influencia mucho más determinante en la gestión de las instituciones. Es por esto, que es preciso señalar algunas de las ventajas directas de la gestión en las organizaciones, así que Ricart y Rodríguez (2004, pp. 58-59) permiten identificar las que se detallan seguidamente:

1 Disminución de la burocracia.

2 Sinergias en los procesos de formación.

3 Disminución de los costes de las auditorías.

4 Aumento de la eficacia y la eficiencia.

\section{Procesos de planificación, organización, dirección, coordinación y evaluación en la gestión del Proyecto de Ética, Estética y Ciudadanía}

Para el análisis de las estrategias de gestión para el desarrollo del Proyecto de Ética, Estética y Ciudadanía en centros educativos, es necesario conocer qué aspectos incorporan los procesos de planificación, organización, dirección, coordinación y evaluación.

\section{La planificación}

Las personas directoras, como gestoras de la educación en esta realidad cambiante, para opinión de Garbanzo y Orozco (2007), requieren de estrategias de intervención que sean efectivas con las demandas que la sociedad y los individuos esperan de la educación, mediante procesos de planificación que permitan diseñar y desarrollar los proyectos oportunamente. Es así, que parte de las funciones de la o el director en el ejercicio de la gestión educativa, la planificación representa una labor trascendental respecto a los cambios de distinta índole que constantemente tienen desarrollo en las estructuras sociales, económicas y culturales sobre las cuales, la educación despliega sus proyectos y programas educativos. 
Rev. Gestión de la Educación, Vol. 4, N² 2, [31-59], ISSN: 2215-2288, julio-diciembre, 2014

DOI: http://dx.doi.org/10.15517/rge.v4i2.15144

URL: http://revistas.ucr.ac.cr/index.php/gestedu

La planificación es un proceso estratégico donde a partir de la definición de actividades previamente planificadas se pretende el desarrollo y alcance de objetivos, en torno a ello, Díaz (2005), citando a Venegas (2004), la define como el conjunto de procedimientos mediante los cuales se hace introducción de una mayor racionalidad y organización en un conjunto de actividades y acciones enlazadas entre sí, que tiene el propósito de influir en el curso de determinados hechos con el fin de obtener una situación planteada como deseable. Así, la planificación representa la toma de decisiones que permiten el desarrollo de planes y actividades del Proyecto de Ética, Estética y Ciudadanía en la construcción de la visión de la institución educativa.

En consonancia con lo anterior, para el proceso de planificación, Newstrom (2007, pp. 60-61) establece una serie de pasos que permiten un orden estructurado de las organizaciones, a lo que señala necesario:

1 Desarrolle un plan maestro

2 Elabore planes de apoyo

3 Ponga números y fechas en todo lo que pueda

4 Defina las tareas

5 Explique el plan a todos los interesados

6 Revise regularmente los planes

\section{La organización}

La organización es un proceso relevante en los centros educativos, puesto que esta debe responder a las necesidades que se presentan en el centro y estar destinada a lograr la eficiencia de los procesos; cabe destacar que la organización, según Koontz, Weihrich y Cannice (2008, p. 110), "es la agrupación de actividades necesarias para lograr objetivos, la asignación de cada grupo a un administrador con la autoridad necesaria para supervisarla y la provisión de coordinación horizontal y vertical en la estructura de la organización". Por ello, es indispensable la presencia de la figura del administrador quien será el encargado de asignar todos aquellos roles necesarios para el buen funcionamiento del centro educativo.

Así, la organización como parte de la gestión que realizan los directivos de las instituciones en el proceso de administrar, debe ser entendida, según Reyes (2005, p. 62) como "(...) la estructuración técnica de las relaciones, que debe darse entre las jerarquías, funciones y obligaciones individuales necesarias en un organismo social para su mayor eficiencia". Es decir, la organización como función administrativa en la educación, puede ser visualizada como el mecanismo que permite el mejoramiento significativo de los esfuerzos que se efectúan en el centro educativo para la implementación de los planes y proyectos escolares.

Ante esta visión de la organización y en relación con las estrategias pertinentes, se considera que esta función de la administración se puede visualizar a través tres etapas definidas por Reyes (2005): "1. Jerarquías; 2. Funciones y 3. Obligaciones" (p. 62). 


\section{La dirección}

La dirección constituye la figura que ejerce la administración para mantener el orden del quehacer organizacional, así como en la preparación de las tareas necesarias para la consecución de los resultados deseados. Así, la dirección en las organizaciones representa la facultad que se le otorga al administrador para poner en marcha las actividades diseñadas para el logro de los objetivos propuestos, a través de un proceso de guía sobre las tareas establecidas.

De allí que en relación con las estrategias de dirección, se requiere dar seguimiento a una serie de pasos que permiten desarrollar una adecuada labor de dirección en las organizaciones, para lo que es necesario, según Reyes (2005): "1. Que se delegue la autoridad; 2. Que se ejerza esa autoridad; 3. Que se establezcan canales de comunicación; 4. Que se supervise el ejercicio de la autoridad" (pp. 307-308).

\section{La coordinación}

La coordinación es una estrategia, la cual para Martins, Cammaroto, Neris y Canelón (2009), consiste en una actividad sistemática y regulada, que requiere el establecimiento de un encuadre. La coordinación exige el establecimiento de reglas explícitas, periodicidad estable y continua, sin ambigüedades, en el que se definan conjuntamente y consensuadamente por las partes implicadas, los elementos a saber. Dentro de la organización y como en toda empresa se llevan a cabo procesos formales e informales que en ocasiones dan un mejor o peor desempeño en una institución. La coordinación, para Jiménez (comunicación personal, correo electrónico recibido el 30 de octubre del 2012):

(...) es el proceso integrador por medio del cual se ajustan las partes entre ellas, de suerte que funcionen armónicamente y sin fricciones o duplicaciones y dando cada sector o individuo su máxima contribución a ese todo, a fin de satisfacer los objetivos sociales de la empresa en particular.

Cuando se da esta integración existe una mayor coordinación que significa un aspecto positivo para la institución, porque se empieza a trabajar mejor. Ante ello, para que se lleven a cabo los procesos de coordinación y funcionen armónicamente, Da Silva (2002) recomienda tomar en cuenta los siguientes principios:

1 Coordinar por medio de un contacto directo.

2 Coordinar el proceso de planeación.

3 Coordinar por medio de relaciones recíprocas.

4 Coordinar en forma de proceso continuo. (p. 188)

5 La evaluación

Licencia Creative Commons 
Es un hecho que la evaluación es un factor que favorece la calidad y mejora de la administración de la educación, por cuanto González (2005, p. 15) indica que esta debe entenderse como "una herramienta que favorece la conciencia crítica y el aprendizaje en pro del mejoramiento de la calidad de nuestras instituciones, pero que requiere de un esfuerzo humano, técnico y económico". Este autor hace hincapié en que la evaluación es una estrategia que debe ser continua, integradora y permitir llevar a cabo mejoras para el logro de la calidad educativa.

Asimismo, la evaluación ya no es concebida como una simple medición, ahora pretende ser una herramienta para la mejora continua de la calidad, a partir del suministro de información para optimizar la toma de decisiones, por tanto para D' Agostino, (1995, p. 14), la evaluación puede ser definida como un "proceso dirigido a comprobar el grado de eficiencia y calidad de todos los elementos que convergen en la realización del hecho educativo, para valorar dicho grado frente a parámetros de referencia y decidir qué hacer respecto de este". Se refieren a las diversas acciones llevadas a cabo desde la administración de la educación que buscan la realización de un objetivo, basándose en la integración de todos los elementos.

De esta manera, en relación con las estrategias de evaluación, se deben tomar en cuenta una serie de acciones que permitan una adecuada evaluación de los proyectos, programas y planes en las instituciones. En este sentido, González (2005) propone las siguientes:

1 Eficacia (Effectiveness)

2 Eficiencia (Efficiency)

3 Pertinencia (Relevance)

4 Sostenibilidad (Viability-Sustainability)

5 Impacto (Impact) (p. 52)

\section{MARCO METODOLÓGICO}

En el estudio para la recolección de la información se seleccionó el diseño de investigación cuantitativa, en tanto que, según McMillan y Schumacher (2005), supone elegir los sujetos de la investigación, las técnicas para la recolección de los datos (cuestionarios, observaciones o entrevistas), los procedimientos para la recolección de la información y la implantación del tratamiento, elementos todos que constituyen la parte metodológica de la investigación. Aunado a esto la investigación se enmarca dentro de un tipo de diseño no experimental, donde para Hernández, Fernández y Baptista (2006, p. 205), los fenómenos se observan "(...) tal y como se dan en su contexto natural, para después analizarlos". Este diseño no experimental es aplicable en el estudio, no hay un condicionamiento del contexto natural o del desarrollo cotidiano de los involucrados en el estudio en los tres colegios, únicamente se observa, se cuantifican y analizan datos para plantear conclusiones y recomendaciones referentes a la implementación del proyecto. 
En relación con el enfoque o paradigma científico utilizado para la presente investigación, es el cuantitativo descriptivo, dado que a criterio de Hernández et ál. (2006, p. 5), emplea "la recolección de datos para probar hipótesis, con base en la medición numérica y el análisis estadístico, para establecer patrones de comportamiento y probar teorías". Con ello se busca lograr la mayor objetividad donde no interfieran los pensamientos del investigador. Por consiguiente, para mantener la línea de la objetividad se analizan datos cuantificables y se fragmentan de manera que contribuyan a dar respuesta a los problemas planteados, y al cumplimiento de los objetivos propuestos.

La población sujeta al estudio corresponde a las y los directores de los centros educativos Colegio Julio Acosta García, Colegio Bilingüe de Palmares y Colegio de Naranjo, un total de tres directores, y al ser estos un número muy bajo y dada la trascendencia de la información que estos otorgan para la investigación, son considerados en su totalidad. Además se toma en cuenta el personal docente de Educación Cívica, Educación Musical y Artes Plásticas que en su totalidad suman 53 funcionarios, quienes están cobijados dentro del Proyecto de Ética, Estética y Ciudadanía. De igual manera, se considerará al estudiantado que integra el Comité Ejecutivo Estudiantil dado que el mismo es un órgano institucional de peso que representa a la población estudiantil, integrado cada comité por siete estudiantes de diferentes niveles académicos.

Respecto a la recopilación de la información, se realizó a través de una entrevista para el encargado de la administración de la educación, así como también para las y los estudiantes miembros del Comité Ejecutivo Estudiantil, y un cuestionario para el personal docente.

\section{RESULTADOS Y SISTEMATIZACIÓN DE LA INFORMACIÓN}

Con la finalidad de analizar las estrategias de gestión para el desarrollo del Proyecto de Ética, Estética y Ciudadanía en los colegios Dirección 3 de la Dirección Regional de Occidente, en el presente apartado se estudian los resultados obtenidos desde los fundamentos teóricos de la investigación con el propósito de ofrecer posibles explicaciones e insumos para la aplicación del proyecto. Para ello, a continuación se desarrollan cada una de las categorías de análisis a partir de los instrumentos aplicados a las y los docentes, administradores de la educación y estudiantes de cada una de las instituciones objeto de esta investigación.

Estrategias de planificación de la administración de la educación para la gestión del Proyecto de Ética, Estética y Ciudadanía

Para investigar sobre las estrategias de planificación para la gestión del Proyecto de Ética, Estética y Ciudadanía, se interrogó alrededor de los indicadores previamente señalados. Con base en estos, al consultarles a las y los docentes si consideran que en el plan institucional operativo anual se contempla el Proyecto mediante actividades de carácter institucional, la gran mayoría de consultados en el Instituto Julio Acosta García (69\%), Colegio Bilingüe de Palmares (50\%) y Colegio de Naranjo (55\%) responden de forma negativa.

Asimismo, al consultar a las y los encargados de la administración de la educación de las instituciones participantes sobre el mismo tema, se obtiene que el criterio dado desde la administración

Licencia Creative Commons 
Rev. Gestión de la Educación, Vol. 4, N² 2, [31-59], ISSN: 2215-2288, julio-diciembre, 2014

DOI:http://dx.doi.org/10.15517/rge.v4i2.15144

URL: http://revistas.ucr.ac.cr/index.php/gestedu

en el Instituto Julio Acosta García no concuerda con la opinión del personal docente, ya que se indica que sí se contempla el Proyecto dentro del plan operativo anual por medio de actividades tales como la Semana Cívica, el Plan de reciclaje y el seguimiento de los planeamientos curriculares de los docentes. Las y los encargados de la administración del Colegio Bilingüe de Palmares y del Colegio de Naranjo, también difieren de la opinión de la mayoría de los docentes, ya que en el caso del Colegio Bilingüe de Palmares, se cumple con la incorporación mediante concursos de expresión cultural, pero se reconoce una deficiencia en el área de Educación Cívica; mientras en el Colegio de Naranjo, se argumenta que se incluye el Proyecto a partir de reuniones con los docentes y respetando las fechas establecidas.

Aunado a ello, a las y los encargados de la administración de la educación también se les preguntó si realizan los planes específicos para el desarrollo de las actividades del Proyecto, cuya respuesta es afirmativa, reforzando así su postura respecto con la inclusión del Proyecto en el plan institucional. Por lo tanto y de acuerdo con los datos obtenidos, es claro que hay un desfase entre lo que opinan las y los docentes y lo que argumentan las y los encargados de la administración de la educación, pues no hay concordancia en los criterios acerca de los procedimientos a seguir para llevar a cabo el Proyecto; es decir de un planeamiento general y de planeamientos específicos de las actividades correspondientes, por lo que no hay objetivos compartidos para cumplir con lo deseado por las organizaciones.

No obstante, en relación con que si las y los encargados de la administración definen tareas a realizar en el tiempo oportuno respecto al Proyecto, el 50\% de los docentes consultados del Instituto Julio Acosta García y del Colegio Bilingüe de Palmares responden afirmativamente sobre esta tarea, mientras el $25 \%$ de los docentes consultados en ambas instituciones no responden a la consulta, datos que contrastan con las respuestas obtenidas en el Colegio de Naranjo donde solo el $25 \%$ de los docentes responden que sí se establecen tareas en el tiempo oportuno, mientras un $50 \%$ lo hace de forma negativa. Además, según la opinión de las y los profesionales encargados de la administración de la educación de las tres instituciones educativas señaladas, afirman establecer las tareas en el tiempo oportuno con respecto del Proyecto; es decir, postura concordante entre las y los directores de los colegios de San Ramón y de Palmares con la mayoría de su personal docente, caso contrario a lo que se manifiesta en el Colegio de Naranjo al contrastar las posiciones.

Al respecto, es importante que se realicen los planes específicos en el tiempo oportuno y que se dividan las tareas; de tal modo que se dé sustento a la planificación con respecto de los objetivos, así como Garbanzo y Orozco (2007) plantean para una administración acertada de la educación, donde es necesario que las y los directores tengan la capacidad de darle la sostenibilidad a los diferentes proyectos que se desarrollan en las instituciones bajo el sustento de los principios de la planificación. Así, en el caso de las instituciones educativas mencionadas, es trascendental un proceso de planificación adecuado e ideado para cumplir con los proyectos establecidos, en este caso el de Ética, Estética y Ciudadanía.

Referente a la opinión de las y los docentes acerca del conocimiento de los propósitos de las actividades institucionales enmarcadas en el Proyecto, es notorio que en el Colegio Julio Acosta García (75\%) y el Colegio de Naranjo (73\%), la mayoría de los docentes afirman no conocer los propósitos de las actividades institucionales. En el Colegio Bilingüe de Palmares, el 43\% de las y los docentes opinan sí conocer los propósitos de las actividades planteadas, y un mismo porcentaje opinan que no los conoce, por lo que hay una discrepancia de opiniones que revela problemas de comunicación. Esta variedad

Licencia Creative Commons 
de criterios contrasta con la opinión de las y los administradores de la educación de los Colegios Julio Acosta García, Bilingüe de Palmares y de Naranjo, quienes dicen si dar a conocer los propósitos de las actividades planteadas.

Así, el problema de una inadecuada comunicación consiste en lo dificultoso que puede resultar hacer que la motivación y la identificación con el centro educativo trabajen a favor de la organización. Ante esta situación, Martins et ál. $(2009$, p. 4) escriben que la o el administrador de la educación "debe actuar como un verdadero comunicador, fuente de motivación, sobre quienes tienen las expectativas todos los actores educativos". Es por ello que un personal sin motivación para el desarrollo del Proyecto, desencadena fallas en el proceso educativo.

Con respecto de si se habilitan espacios para dar a conocer el propósito del Proyecto desde la administración de los centros educativos, el $75 \%$ de los docentes consultados en el Instituto Julio Acosta García, opinan que esos espacios no se ven habilitados, mientras que desde la dirección de este centro educativo se dice sí habilitar espacios, los cuales a pesar de ser solicitados en los instrumentos no son especificados. Asimismo, las y los estudiantes de este mismo colegio, al planteárseles esta misma interrogante, responden que hay carencia en estos aspectos, ya que si bien es cierto no están restringidos, falta mayor integración entre los espacios y recursos que posee la institución para un mayor aporte al Proyecto.

Por su parte, en el Colegio Bilingüe de Palmares, el $43 \%$ de los docentes consultados responde que no hay espacios en la institución para dar a conocer el Proyecto, pero también un $43 \%$ afirma que sí se dan y un $14 \%$ no respondió. Con esto, nuevamente se denota el problema de la comunicación, ya que ante este cuestionamiento, el encargado de la administración del centro educativo responde afirmativamente, pero no especifica los medios por los cuales habilita y da a conocer estos espacios. Además, las y los estudiantes consultados en este colegio, dicen que los espacios que tienen para conocer el Proyecto es cuando observan a otros estudiantes plasmando el Proyecto en los pasillos.

A su vez en el Colegio de Naranjo, ante esta misma pregunta, un alto porcentaje de los docentes consultados responden de forma negativa con un 82\%, mientras desde la dirección de este centro educativo se afirma habilitar esos espacios, indicando que el medio que se emplea para ello es el cronograma oficial enviado desde el Ministerio de Educación Pública. Asimismo los estudiantes de este colegio que fueron consultados, especifican que los espacios habilitados son la explicación docente y lo que observan en el colegio.

Así, partiendo de los datos obtenidos es importante recalcar que las y los administradores de la educación en cuanto a la planificación, deben propiciar los espacios oportunos para que todos los partícipes del proceso educativo se enteren e integren en los proyectos. Ante esta tarea, Mora (2011, p. 11) plantea que la o el administrador de un centro educativo, "(...) es quien tiene la tarea de dirigir todo el proceso desde dos ámbitos de trabajo: el administrativo y el académico, con la articulación de las competencias de todo su personal". Pero para ello es

Licencia Creative Commons 
Rev. Gestión de la Educación, Vol. 4, № 2, [31-59], ISSN: 2215-2288, julio-diciembre, 2014

DOI: http://dx.doi.org/10.15517/rge.v4i2.15144

URL: http://revistas.ucr.ac.cr/index.php/gestedu

fundamental la apertura de esos espacios para lograr el equilibrio entre lo administrativo y lo académico, aspecto que la planificación permite desarrollar.

En cuanto a la elaboración del cronograma de las actividades alrededor del Proyecto, en el Colegio Julio Acosta García (69\%) y el Colegio de Naranjo (73\%) los resultados son congruentes, siendo el porcentaje más alto el de los docentes que opinan que no hay un cronograma de las actividades, pero en el Colegio de Palmares, la mayoría de los docentes (36\%) son quienes afirman la existencia de un cronograma de actividades. Además, de acuerdo con la posición de las y los encargados de la administración de la educación consultados, estos concuerdan en argumentar tener un cronograma de las actividades a realizar.

Es apreciable, entonces, la diferencia de lo manifestado por las y los docentes en relación con sus directores en lo que se refiera a la existencia de un cronograma, por lo que se puede estar evidenciando nuevamente un desfase en la comunicación. Ante ello cabe recalcar que, una planificación con un cronograma establecido pero que no se da a conocer a las y los miembros de la organización genera una limitante, ya que no todos los integrantes estarán informados de lo que deben hacer respecto al Proyecto en el momento oportuno para el avance de lo planeado y el logro de resultados.

Por tanto, y considerando el análisis de los datos referentes a las preguntas relacionadas al proceso de la planificación, se puede argumentar que no hay una adecuada planificación puesto que la misma es percibida así por los docentes y estudiantes. Además, la opinión de los docentes difiere de las posturas de las y los encargados de la administración de la educación consultados, ya que estos difieren respecto del cumplimiento de las variables señaladas como necesarias para llevar a cabo un proceso de planificación del Proyecto.

Asimismo, en cuanto a la elaboración del plan institucional operativo anual, es claro que las y los encargados de la administración de la educación de los centros educativos en estudio, elaboran el plan; sin embargo, los docentes no perciben la inclusión en este de actividades que solventen las necesidades que se deben cubrir según los propósitos del Proyecto de Ética, Estética y Ciudadanía. Además, el hecho de que falte la inclusión del Proyecto dentro de la planificación, no permite la gestión de estrategias de apoyo o de planificación específicas.

Igualmente, los docentes manifiestan la carestía en la definición de roles o distribución de responsabilidades con base en la aplicación del Proyecto, así como el problema de la no integración de la mayoría de la comunidad educativa en las actividades planteadas, debido a que desde la gestión, la planificación no ha contemplado informar las metas trazadas en relación con el Proyecto con la misión y visión de los centros educativos. Además, no se fomentan espacios para la reflexión y seguimiento del trabajo de los involucrados con el Proyecto. 
Estrategias de Organización en el desarrollo del Proyecto de Ética, Estética y Ciudadanía

En la investigación realizada respecto a las estrategias de organización, se trabajó tomando en cuentas los indicadores necesarios para que se realice una adecuada organización dentro de las instituciones donde se ejecuta el Proyecto. Frente a ello, en cuanto a la asignación de responsabilidades por parte del gestor, las y los encargados de la administración de la educación afirmaron que sí asignan dichas responsabilidades para con las y los docentes. Sin embargo, al preguntarle a los docentes, la mayoría del Colegio Bilingüe de Palmares (57\%) y del Colegio de Naranjo (55\%) responde que sí se asignan responsables; no obstante, en el Colegio Julio Acosta García solo un 44\% responde de manera afirmativa, siendo la mayoría de docentes (56\%) los que afirman que no se asignan responsables para la ejecución de cada actividad dentro del Proyecto.

Con esos datos se determina que en la mayoría de las instituciones en las que se abordó la temática se asignan responsables para el desarrollo de las actividades, lo cual forma parte de la administración educativa ya que, como bien dice Vargas $(2008$, p. 2) esta constituye una actividad práctica que "(...) supone una deliberación y una toma de decisiones responsable, que permita a los profesores de la escuela asumir un papel activo en la construcción de una comunidad educada y capaz de establecer un orden dinámico y democrático". Lo anterior, determina que se ha abordado la temática de organización de una manera eficiente.

Asimismo, en cuanto a si desde la administración del centro educativo se establecen las funciones que deben desempeñar los docentes involucrados en la ejecución del Proyecto, la mayoría de docentes del Colegio Julio Acosta García (75\%), Colegio Bilingüe de Palmares (57\%) y Colegio de Naranjo (64\%) contestaron que no se establecen dichas funciones. Al respecto, las y los encargados de la administración de la educación, contrario a lo anterior, aseguran establecer las funciones que deben desempeñar las y los docentes para con el Proyecto, una posición donde se denota entonces que la gestión decae, pues no se está asumiendo en forma completa la organización, debido a que esta contempla como lo sugiere Reyes (2005, p. 62) "(...) la estructuración técnica de las relaciones, que debe darse entre las jerarquías, funciones y obligaciones individuales necesarias en un organismo social para su mayor eficiencia". Por tanto, esa estructuración de funciones no se establece completamente, ya que las partes involucradas en este caso no llegaron a un acuerdo.

Por otra parte, en cuanto a la asignación de tareas específicas a cada uno de los involucrados en el Proyecto por parte de las y los administradores de la educación, se puede inferir que esta no se cumple a cabalidad, debido a que en el Colegio Julio Acosta García (75\%), el Colegio de Palmares (72\%) y el Colegio de Naranjo (73\%) las y los docentes opinan no se asignan tareas específicas. Estos datos; sin embargo, son contrarios a lo mencionado por las y los encargados de la administración de la educación de los tres centros educativos mencionados respecto al cumplimiento de este indicador, por lo que se visualizan carencias.

Licencia Creative Common 
Rev. Gestión de la Educación, Vol. 4, № 2, [31-59], ISSN: 2215-2288, julio-diciembre, 2014

DOI: http://dx.doi.org/10.15517/rge.v4i2.15144

URL: http://revistas.ucr.ac.cr/index.php/gestedu

Así, los resultados anteriores cuestionan la gestión dentro de los centros educativos estudiados, ya que no se muestra la integración de lo que dicen hacer los gestores y de lo que están percibiendo las y los docentes. Por tanto, en cuanto a la asignación de responsabilidades, establecimientos de funciones y asignación de tareas a las y los docentes por parte de las y los encargados de la administración en lo referente al Proyecto de Ética, Estética y Ciudadanía, se infiere que las estrategias de organización no se cumplen de manera completa por todos los sujetos partícipes del proceso en cuestión.

\section{Estrategias de Dirección en el desarrollo del Proyecto de Ética, Estética y Ciudadanía}

Al hacer referencia al proceso de dirección llevado a cabo en las instituciones educativas, cuando se consultó si se delegan funciones al personal docente respecto a la tarea de control y supervisión del Proyecto, las y los administradores de la educación de las tres instituciones estudiadas contestaron que realizan dicha labor. En el Colegio Julio Acosta García se realiza mediante la elaboración de formularios, mientras en el Colegio Bilingüe de Palmares se evidencia a partir de los resultados obtenidos en la institución, y en cuanto al Colegio de Naranjo se indica supervisar por medio de reuniones periódicas con las y los docentes involucrados y definiendo fechas para la ejecución institucional y circuital de las actividades.

Asimismo, en cuanto al personal docente, en el Colegio Julio Acosta García las y los educadores dijeron ser evaluados mediante la solicitud de avances, entrevistas y entrega de un informe final del proyecto, esto mientras algunos dicen que no existe ningún tipo de supervisión. En el Colegio Bilingüe de Palmares la mayoría de docentes afirma que esta tarea se realiza mediante la asignación de un coordinador quien es el que supervisa los proyectos, mientras otros opinan que dicha delegación de funciones se realiza mediante encargados o simplemente manifestaron desconocer si existía alguna forma de supervisión. Por último, en el Colegio de Naranjo afirmaron que se realizaba por medio de los comités, planes que se presentan en las actividades, comisiones interdisciplinarias, reuniones por departamento y con la o el director.

Así, las actividades realizadas por los administradores de la educación dentro de los centros educativos giran en torno a una adecuada implementación de las estrategias directivas, en cuanto Reyes (2005, p. 305) dice que "la dirección es aquel elemento de la administración en el que se logra la realización efectiva de todo lo planeado, por medio de la autoridad del administrador, ejercida a base de decisiones, ya sea tomadas directamente, ya con más frecuencia, delegando dicha autoridad, y se vigila simultáneamente que se cumplan en la forma adecuada todas las órdenes emitidas". Por lo tanto, el delegar y supervisar las funciones para llevar a cabo el proyecto son acciones que deberían realizarse desde la administración. 
No obstante, y en cuanto a la delegación de funciones, aunque los tres administradores de la educación aseguraron delegar funciones durante el desarrollo del proyecto, el personal docente no estuvo del todo de acuerdo, ya que en el Colegio Julio Acosta García el 50\% de las y los docentes no estaban de acuerdo, mismo valor porcentual de quienes sí lo estaban, misma situación que se presentó con el Colegio Bilingüe de Palmares donde la opinión se dividió en valores de $50 \%$ en respuestas opuestas; mientras en el Colegio de Naranjo un $9 \%$ indicó que si se delegan funciones a las y los docentes, el $64 \%$ se opuso y un $27 \%$ no respondió.

Por otra parte y en cuanto a la posibilidad que ofrecen las y los administradores de la educación a las y los docentes de tomar decisiones respecto al Proyecto, en el Colegio Julio Acosta García (69\%) y el Colegio de Palmares (79\%), aseguran tener la posibilidad para la toma de decisiones, misma posición que sus administradores de la educación, caso contrario al Colegio de Naranjo donde el 55\% afirma que desde la dirección no se faculta al docente para tomar decisiones. Sin embargo, para una adecuada administración de la educación se tornan necesarios algunos requerimientos, señalados por Garbanzo y Orozco (2010), como la capacidad por experimentar o el gusto por el riesgo, que se pueden ver reducidos en la administración educativa al no existir confianza sobre el personal docente para la facultad para tomar decisiones, lo cual minimiza la capacidad de la gestión de la educación.

Asimismo, al consultar a las y los docentes de las tres instituciones acerca del empleo de herramientas de comunicación como medios de control y supervisión de las actividades desarrolladas en el marco de los objetivos del Proyecto, en el Colegio Julio Acosta García (63\%) y en el Colegio de Naranjo (55\%) la mayoría indicó que no se mantienen canales de comunicación como medio de supervisión, a diferencia de lo planteado en el Colegio Bilingüe de Palmares donde el 64\% respondió que dichos canales sí existen dentro de la institución. Esto, contrasta con la opinión de las y los encargados de la administración, quienes dicen sí tener canales de comunicación como medio de control y supervisión, lo cual indica que solo se cuenta con ciertas estrategias de dirección, ya que como citan Zambrano y Marval (2008, p. 620), la dirección "es fundamental, pues su racionalidad viabiliza alcanzar lo planificado, dada la autoridad y coordinación de actividades que permite". Por lo tanto, esta no debería ser deficiente ya que es un proceso de suma importancia dentro de la gestión de la educación.

En síntesis, la delegación de funciones por parte del administrador de la educación para con las y los docentes, la facultad del personal en la toma de decisiones, el mantenimiento de canales de comunicación como medio de control y supervisión como parte del proceso de dirección del Proyecto de Ética, Estética y Ciudadanía, se cumple en algunos casos. No obstante, se siguen presentando algunos aspectos que deben mejorarse en cada una de las instituciones estudiadas, debido a la no congruencia de muchas de estas temáticas con respecto de sus superiores.

Licencia Creative Commons 
Rev. Gestión de la Educación, Vol. 4, № 2, [31-59], ISSN: 2215-2288, julio-diciembre, 2014

DOI: http://dx.doi.org/10.15517/rge.v4i2.15144

URL: http://revistas.ucr.ac.cr/index.php/gestedu

\section{Estrategias de coordinación para la gestión del Proyecto de Ética, Estética y ciudadanía}

Con la finalidad de identificar las estrategias de coordinación empleadas por las y los administradores de la educación en la gestión del Proyecto de Ética, Estética y Ciudadanía, se consultó a las y los encargados de la administración de la educación de las instituciones investigadas, si se da un involucramiento de los demás actores educativos relacionados con el Proyecto, donde se obtuvo que los tres administradores de la educación responden afirmativamente. No obstante, existe un contraste de opiniones, dado que al preguntar a las y los docentes, en el Colegio Julio Acosta García (75\%), el Colegio Bilingüe de Palmares (55\%) y el Colegio de Naranjo (49\%) opinan que no.

Sumado a ello, de acuerdo con el criterio del Comité Ejecutivo Estudiantil de los tres colegios, estos sienten que sí son incluidos en los planes y proyectos educativos asumidos por la institución, tal y como lo señala el Comité Ejecutivo Estudiantil del Instituto Julio Acosta García (2013) donde consideran que en tiempos pasados al estudiante no se le involucraba con los asuntos a nivel administrativo; no obstante, en la actualidad se cuenta con una mayor disposición por parte de la administración de la institución educativa en incluirlos más en diferentes actividades. Es así que, al considerar todas las opiniones, se evidencia una debilidad en el cumplimiento de este indicador por parte de las y los administradores de la educación principalmente sobre el cuerpo docente, quienes constituyen el grupo excluido.

En este sentido, Rodríguez (2003) sugiere que todos los miembros de la comunidad educativa, principalmente el personal docente, debe conocer, desde la dirección, qué, para qué y quién está haciendo las tareas y actividades. Por lo tanto, es necesario que se mantenga una coordinación constante para la planeación de los diferentes procesos dentro de la gestión del Proyecto, con el objetivo que desde un principio y conforme se vaya desarrollando, exista una articulación entre las y los administradores de la educación, docentes y estudiantes a cargo de ejecutar las actividades.

Asimismo, al consultarles a los docentes sobre la articulación constante por parte de las y los administradores de la educación de las actividades incluidas en la planeación del Proyecto, para las y los encargados de la administración de la educación del Colegio Julio Acosta García y Colegio de Naranjo, la articulación de las actividades del Proyecto es un hecho, opinión contraria para el personal docente de estas mismas instituciones, puesto que un $75 \%$ y un $73 \%$ en orden respectivo, contestan negativamente. Esto, es opuesto al Colegio Bilingüe de Palmares donde el director como las y los docentes concuerda que desde la administración no se ha logrado mantener un proceso continuo para la articulación de las actividades.

Lo anterior, permite hacer referencia a Rodríguez (2003) para quien se debe involucrar en las diferentes etapas, ya sea elaboración de planes, programas o planificación de actividades a todos los coordinadores de departamento, docentes y demás recursos, lo cual es indispensable para el cumplimiento del proceso de coordinación, de lo contario se cuenta con una deficiencia 
en este sentido. Además, es necesario que los departamentos involucrados en el desarrollo del Proyecto, junto con la administración, constituyan una unidad de trabajo dado que la organización educativa no se puede administrar como un conjunto de departamentos independientes, sino todos estos articulados.

Además, en cuanto a los procesos de retroalimentación como una estrategia de coordinación en la gestión, las y los administradores de la educación en el Colegio Julio Acosta García como en el Colegio de Naranjo indican que sí se da una retroalimentación, a diferencia del Colegio Bilingüe de Palmares donde se responde lo contrario. No obstante, de acuerdo con las y los docentes, la gran mayoría en el Colegio Julio Acosta García (81\%), Colegio Bilingüe de Palmares (64\%) y el Colegio de Naranjo (100\%) coinciden en que desde la dirección no se facilitan espacios para la retroalimentación durante el desarrollo del Proyecto de Ética, Estética y Ciudadanía. Da Silva (2002, p. 188), insiste en la necesidad de propiciar un ambiente de "relaciones recíprocas, en cuyo caso una parte influye en todas las otras partes y es influida por ellas"; así los partícipes pueden aprender unos de otros, compartir ideas, técnicas, actividades, todas con el objetivo de desarrollar el Proyecto forma integral.

Finalmente, al consultar si la gestión del Proyecto se hace de forma continua, la opinión del personal docente del Colegio Julio Acosta García (88\%), Colegio Bilingüe de Palmares (50\%) y Colegio de Naranjo (82\%) señala que las y los encargados de la administración de la educación no logran poner en práctica acciones que conduzcan a una gestión de forma constante. No obstante, las y los administradores del Colegio Julio Acosta García y Colegio de Naranjo, a excepción del Colegio Bilingüe de Palmares, opinan lo contrario al personal docente, permitiendo inferir que la gestión del Proyecto no se hace de forma continua.

En relación con lo anterior, se concluye que en la estrategia de coordinación, en cuanto a la integración de los diversos niveles de la organización, presenta disparidad de posiciones acerca de lo expuesto por las y los encargados de la administración de la educación y lo señalado por el cuerpo docente; por tanto, la integración como estrategia de coordinación está presente en alguna medida, pero se requiere mejorar. Además, en cuanto a si se articulan constantemente las actividades con el objetivo de establecer adecuadamente el proceso de planeación del Proyecto, se obtiene que igualmente las opiniones del personal docente en una gran mayoría son negativas, siendo necesario que se dé una verdadera y constante inclusión del personal y de todos los demás involucrados. Asimismo, es necesario un proceso de retroalimentación y de continuidad de las tareas realizadas alrededor del Proyecto, debido a que al igual que los anteriores indicadores de coordinación, no se dan en su totalidad. 
Rev. Gestión de la Educación, Vol. 4, № 2, [31-59], ISSN: 2215-2288, julio-diciembre, 2014

DOI: http://dx.doi.org/10.15517/rge.v4i2.15144

URL: http://revistas.ucr.ac.cr/index.php/gestedu

\section{Herramientas de evaluación utilizadas por los administradores de la educación para el desarrollo del Proyecto de Ética, Estética y Ciudadanía}

Para investigar sobre las herramientas de evaluación empleadas por los administradores de la educación para el desarrollo del Proyecto de Ética, Estética y Ciudadanía, se consultó a las y los docentes de las instituciones investigadas si consideraban que se alcanzaron los objetivos definidos desde la gestión respecto al plan operativo anual para el Proyecto de Ética, Estética y Ciudadanía, de donde se obtuvo que la mayoría del Colegio Julio Acosta García (56\%) y del Colegio de Naranjo (82\%) refieren que no se alcanzaron los objetivos. No obstante, el Colegio Bilingüe de Palmares presenta datos opuestos, donde la mayoría (50\%) opinan que sí se cumplieron las metas fijadas.

Además, las y los administradores de la educación de los colegios en estudio, refieren que sí se alcanzaron los objetivos definidos según el plan operativo anual para el Proyecto de Ética, Estética y Ciudadanía. Sin embargo, como señala el Ministerio de Educación Pública (2009, p. 23), esta situación es de considerar, pues las opiniones varían entre las y los docentes, debido a que la evaluación no es vista como "una acción colectiva, reflexiva, estimuladora de la autonomía y la criticidad", por lo que se contrapone a lo que debería ser una gestión articulada, responsable de que la evaluación del proyecto se realice a través de un proceso de construcción colectiva.

Aunado a ello, en relación con si las y los encargados de la administración de la educación efectúan procedimientos que permitan identificar que los recursos empleados para el desarrollo del Proyecto estuvieron acorde con los resultados obtenidos, las y los docentes del Colegio Julio Acosta García (69\%), Colegio Bilingüe de Palmares (64\%) y del Colegio de Naranjo (73\%) en su mayoría indican que no se realizan en sus instituciones. En relación con esto, a criterio del personal docente, en ninguna de estas instituciones la o el administrador de la educación vela porque se lleve a cabo el Proyecto de Ética, Estética y Ciudadanía bajo criterios elevados de eficiencia, vista esta por González (2005, p. 52) como "el análisis que pone en comparación los resultados obtenidos con los medios utilizados"; es así como no se puede establecer una comparación entre lo que se ha alcanzado con el Proyecto y cuáles herramientas o mecanismos fueron empleados, con el fin de constatar su pertinencia.

Por su parte, las y los administradores de la educación refieren que sí se efectúan procedimientos que permiten identificar los recursos empleados para el desarrollo del Proyecto en sus respectivas instituciones. No obstante, se demuestra que existe contradicción entre las opiniones otorgadas por el personal docente y las y los encargados de la administración de la educación, lo que indica que no existe una unidad de acción que logre armonizar los métodos de trabajo, por lo que se requiere de la visualización de la administración de la educación, tal como indica Vargas (2008, p. 2), al señalar que una actividad práctica "(...) supone una deliberación y una toma de decisiones responsable, que permita a los profesores de la escuela asumir un papel activo en la construcción de una comunidad educada y capaz de establecer un orden dinámico y democrático". Desde la administración de la educación es indispensable que 
el gestor mantenga adecuados métodos de evaluación de la eficiencia del proyecto de manera que permita constatar la pertinencia del Proyecto.

Con respecto de si la institución cuenta con criterios que permiten identificar que la gestión del Proyecto respondió verdaderamente a las necesidades de aquellos a quienes fue dirigido, las y los docentes del Colegio Julio Acosta García (69\%), Colegio Bilingüe de Palmares (50\%) y Colegio de Naranjo (73\%) señalan que no existen dichos criterios. Ante ello, las y los administradores de la educación difieren en opiniones, debido a que en los colegios de Palmares y Naranjo se concuerda con lo planteado por el personal docente de estas instituciones, mientras en el caso del Instituto Julio Acosta García, la posición de la administración es opuesta a lo establecido por las y los educadores, lo cual puede deberse a una falta de coordinación y de comunicación de los diversos equipos de trabajo.

Se demuestra de esta manera que, según los indicadores y las opiniones señaladas, no existe una constatación de la pertinencia del Proyecto de Ética, Estética y Ciudadanía por parte de las y los profesionales de la administración de la educación, con el fin de valorar si este respondió verdaderamente a las necesidades de aquellos estudiantes a quienes fue dirigido. Esta falta de verificación muestra que no hay un vínculo firme con el Proyecto, como lo asevera González (2005, p. 21), puesto que la evaluación no es concebida como una "acción transversal al ciclo de vida de los proyectos y programas de desarrollo". Es así que se requiere del involucramiento de las partes en el proceso de la administración de la educación para una adecuada unidad de acción.

Por otra parte, con respecto de los procedimientos adecuados para conocer la permanencia del Proyecto a través del tiempo sobre la población meta, la mayoría de las y los docentes del Colegio Julio Acosta García (75\%), Colegio Bilingüe de Palmares (64\%) y Colegio de Naranjo (82\%) dicen no conocerlos. Aunado, según la opinión de las y los administradores de la educación, en el caso del Colegio Bilingüe de Palmares y el Colegio de Naranjo, señalan que en sus instituciones no se poseen procedimientos adecuados para conocer la permanencia del Proyecto a través del tiempo sobre la población meta, mientras que desde la administración del Colegio Julio Acosta García se señala que sí, en una ambivalencia respecto a las opiniones expuestas por el personal docente.

Asimismo, en relación con si se monitorea el Proyecto para identificar los log ros alcanzados, las y los docentes del Colegio Julio Acosta García (69\%) y Colegio de Naranjo (91\%) señalan que no, lo que indica que el criterio de impacto del Proyecto es deficitario; no obstante, las y los docentes del Colegio Bilingüe de Palmares indican en un $50 \%$ que sí se monitorea el Proyecto, y un $50 \%$ que no se hace este seguimiento, lo que indica que una parte de la población de docentes es incapaz de identificar los alcances. Además, la opinión de las y los administradores de la educación, en el caso del Colegio de Naranjo y del Julio Acosta García, señalan que en sus instituciones sí se monitorea el Proyecto, lo cual revela una contradicción respecto a las opiniones del personal docente; mientras en el Colegio Bilingüe de Palmares se señala lo contrario concordando con lo señalado por las y los docentes de su institución, motivo por lo cual se le dificulta el compartir resultados inherentes al Proyecto. 
Rev. Gestión de la Educación, Vol. 4, № 2, [31-59], ISSN: 2215-2288, julio-diciembre, 2014

DOI: http://dx.doi.org/10.15517/rge.v4i2.15144

URL: http://revistas.ucr.ac.cr/index.php/gestedu

Ante esta interrogante, se evidencia que no hay consenso en la mayoría de las respuestas por parte de las y los docentes y administradores de la educación, y por lo tanto, el impacto entendido por González (2005, p. 52) como el "criterio que apunta a la valoración de todos los efectos surgidos en el entorno del Proyecto en cualquiera de los ámbitos de la vida social, así sean positivos o negativos, esperados o no", no es funcional dentro de estas instituciones educativas y que por lo tanto requiere que cada uno de sus miembros actúe para lograr una gestión que brinde el éxito del Proyecto en la institución. Es así que, desde el punto de vista de la administración de la educación, las herramientas de la evaluación son insuficientes, ya que la forma en que se generan impide una adecuada retroalimentación de las actividades y de la gestión educativa.

\section{Aspectos por mejorar y elementos positivos de la gestión del Proyecto de Ética, Estética y Ciudadanía}

Para investigar los aspectos por mejorar y los elementos positivos de la gestión del Proyecto mediante la técnica FODA, y de acuerdo con la información otorgada por las y los encargados de la administración de la educación en las instituciones seleccionadas, existen una serie de elementos por enriquecer alrededor del Proyecto, donde destacan los criterios referentes a la necesidad de que el personal docente funcione como un guía en la realización de los proyectos, así como la necesidad de que los proyectos respondan más adecuadamente a las realidades institucionales y de la comunidad educativa, aspectos que representan debilidades de la gestión del Proyecto. Únicamente, el encargado de la administración de la educación del Colegio de Naranjo, manifestó el poco apoyo logístico por parte del Ministerio de Educación Pública en relación con el Proyecto, lo cual corresponde a una amenaza para la gestión, debido a que la participación activa del Ministerio permite que el personal docente y las y los directores posean las herramientas y los conocimientos necesarios para llevar a buen término la función de acompañamiento del proceso de enseñanza y aprendizaje del estudiantado.

Por otra parte, las y los docentes señalan la falta de una adecuada planificación institucional por departamentos y a nivel de docente en relación con el Proyecto, la necesidad de mayores y mejores estructuras de comunicación, monitoreo, control, coordinación y retroalimentación entre el personal docente y la administración, así como la poca cantidad de tiempo y de lecciones para el desarrollo de las distintas actividades del Proyecto, constituyendo todos estos elementos en debilidades en la gestión. Además, se plantean como aspectos por mejorar, el tema de la falta de capacitaciones para todos los involucrados por parte del Ministerio de Educación Pública, y un mayor apoyo logístico respecto a materiales y asistencia técnica por parte de las autoridades educativas, criterios que representan amenazas para una adecuada implementación de las estrategias de gestión del Proyecto.

Asimismo, el Comité Ejecutivo Estudiantil de las distintas instituciones analizadas, concuerda en que es necesario un mayor interés por parte de la institución y del personal docente en la ejecución de los proyectos, aspecto que se relaciona de igual manera con la falta de motivación que 
el estudiantado de los colegios Julio Acosta García y Bilingüe de Palmares señalan en relación con la ejecución de los proyectos, que resultan poco atractivos. Todos estos elementos corresponden a debilidades en la gestión del Proyecto; mientras que la amenaza que se externa únicamente por parte del Comité Ejecutivo Estudiantil del Instituto Julio Acosta García, está en relación con los contenidos que se siguen evaluando de la misma manera en cuanto a las pruebas de bachillerato.

Así, en contraste con la posición de las y los encargados de la administración de la educación y el personal docente de las instituciones estudiadas, destaca el hecho de que las y los docentes plantean problemas de planificación que conducen a resultados poco positivos, tanto a nivel de institución como por departamentos, criterio compartido por las y los directores de los centros educativos, quienes a su vez señalan el poco compromiso docente para con la realización de los proyectos educativos. Estos aspectos concuerdan con la exigencia estudiantil de una participación activa por parte de la institución y del personal docente para con la realización de las actividades del Proyecto, donde se hace necesario un mayor equilibrio entre los intereses del estudiantado y la labor que lleva a cabo toda la organización.

Todas estas consideraciones responden a lo señalado por Ricart y Rodríguez (2004) acerca de la importancia de un aumento en la eficiencia y en la eficacia de los procesos de gestión, en tanto la implementación de un sistema integrado, permite el mejoramiento de las actividades y funciones que cumplen las organizaciones a través de la simplificación de sus estructuras. Una mejora en la eficiencia y la eficacia de la gestión del Proyecto posibilita el involucramiento de los docentes en la elaboración de los planes y proyectos, así como la incorporación de estos en el plan operativo anual de cada institución, acciones que permiten una mayor intervención de la administración con la ejecución de los proyectos estudiantiles a nivel institucional, así como en el proceso de supervisión de los planes y actividades que se adscriben a estos proyectos, de manera que se pueda dar respuesta satisfactoria a las necesidades del estudiantado para con el abordaje de los contenidos, la dinámica del desarrollo de las lecciones y la preparación adecuada para las pruebas trimestrales y de bachillerato.

Por otra parte, en lo que concierne a los aspectos positivos de la gestión del Proyecto de Ética, Estética y Ciudadanía, las y los profesionales encargados de la administración de la educación indican que el Proyecto representa una forma de trabajo colaborativo y en equipo, así como la posibilidad de visualizar el entorno por parte de las y los estudiantes a través de las actividades anexas al Proyecto, la integración de las y los jóvenes a la comunidad, y el desarrollo de habilidades como lo es la investigación, todos estos aspectos representando fortalezas de la gestión. Asimismo, se plantea la posibilidad de interacción de los centros educativos con la comunidad, constituyendo esta característica una oportunidad para mantener un acercamiento sano entre las instituciones y la realidad del contexto.

Además, el personal docente de los centros educativos analizados, indica aspectos concernientes al desarrollo de habilidades investigativas y expositivas, lo que a su vez fomenta

Licencia Creative Commons 
Rev. Gestión de la Educación, Vol. 4, № 2, [31-59], ISSN: 2215-2288, julio-diciembre, 2014

DOI: http://dx.doi.org/10.15517/rge.v4i2.15144

URL: http://revistas.ucr.ac.cr/index.php/gestedu

el pensamiento crítico y el análisis entre las y los estudiantes, el desarrollo de la creatividad, la originalidad, fomento a talentos y valores, así como el trabajo en equipo en relaciones de cooperación y retroalimentación al fomentarse mayor participación del estudiantado en la toma de decisiones, el aporte de ideas y la socialización, el fomento de identidad entre el estudiantado y la institución, esto como espacios para la realización de los proyectos educativos en respuesta a las necesidades de las instituciones, criterios que corresponden a fortalezas de la gestión del Proyecto. Mientras, la posibilidad de que el estudiantado genere un aporte hacia un público meta, así como el interés por darle solución a algunos de los problemas que se presentan en las comunidades, corresponden a oportunidades en la gestión del Proyecto.

Además, en la opinión del Comité Ejecutivo Estudiantil de las instituciones investigadas, se identifican como elementos positivos el beneficio que genera para las y los estudiantes realizar un proyecto debido a la posibilidad de elegir actividades y temas, así como en su comparación evaluativa frente a las pruebas escritas, y el desarrollo del conocimiento mediante la investigación, aspectos que se clasifican como fortalezas en la gestión del Proyecto. Asimismo, las y los estudiantes consultados no señalaron aspectos concernientes a oportunidades respecto a la gestión del Proyecto en cuestión.

De esta manera y en contraste con lo expresado por el personal docente y las y los encargados de la administración de la educación, se muestra concordancia en relación a criterios como el desarrollo de habilidades investigativas y expositivas como una fortaleza que se desprende de la ejecución de los proyectos y actividades consecuentes. Este aspecto, al igual que el trabajo en equipo y la interacción de las y los estudiantes y las instituciones educativas con la realidad del contexto, representan el resultado de una labor que no descansa únicamente en la obra que realizan los profesionales encargados de la administración de la educación, puesto que como lo señala Venegas (2011) la gestión escolar constituye colocar la función del director en relación con el trabajo colegiado del personal, de manera que este sea partícipe con la comunidad educativa; por tanto, la gestión representa una tarea de un grupo amplio de trabajo que debe ser orientado por las y los directores.

Es decir, la gestión de la educación que se efectúa desde la figura del profesional encargado de la administración de la educación, está en el diseño de las estrategias de acción, la disposición de los recursos, el control y la supervisión de las tareas que se efectúan, y en la apertura de espacios para la retroalimentación del estudiantado con el personal docente y la administración, esto como producto de un trabajo articulado, organizado y coordinado que responda a una definición clara y precisa de los objetivos y las metas que deben cumplir cada uno de los miembros de la organización. Así, el resultado de una adecuada gestión institucional se evidenciará en los objetivos alcanzados y en las necesidades satisfechas para todos los integrantes de la comunidad educativa.

Por tanto y de acuerdo con lo anterior, se puede mencionar que si bien existe concordancia en algunos aspectos relacionados con la gestión de los proyectos, los diferentes subgrupos 
analizados manifiestan desde su espacio de trabajo, la manera como el accionar de los proyectos estudiantiles responde a algunas de sus necesidades educativas, pero sin denotar una adecuada línea de gestión que amalgame las distintas actividades del proyecto. Esto, atiende al balance entre los aspectos positivos y los elementos por mejorar de la gestión, debido a que estos últimos referencian la necesidad de una mayor concatenación entre la realidad institucional y el contexto comunal, así como lo referente a una adecuada planificación a nivel de dirección, departamento y labor docente, condiciones que atentan contra un efectivo alcance de los resultados.

\section{Conclusiones, recomendaciones y consideraciones finales}

La información obtenida a partir de las entrevistas y las encuestas, analizada según lo expuesto en el marco teórico de la presente investigación permite emitir las siguientes conclusiones según las categorías de análisis:

En cuanto la planificación para los estudiantes y docentes hace falta mayor orden e integración de los miembros de la organización. En referencia a la organización se obtiene que la asignación de funciones se desarrolla de manera adecuada, contrario al establecimiento de tareas para los docentes. Sobre la dirección se concluye que para que sea efectiva debe estar presente la delegación de funciones, el ejercicio de la autoridad, el establecimiento de canales de comunicación y supervisión de la autoridad, aspectos que presentan debilidad en las instituciones sujetas al estudio. En lo que respecta a la coordinación para los docentes no se integra totalmente a los involucrados de la gestión del proyecto, así como en la integración del personal. Sobre la evaluación hay una carencia de una evaluación constante, integradora y articulada del personal docente y administrativo. Además en cuanto los aspectos por mejorar de la gestión del proyecto falta una mayor concatenación entre el centro educativo y la realidad, así como una adecuada planificación y comunicación; así mismo una carencia en la sinergia necesaria para el desarrollo del proyecto. Y por último en lo que respecta en los aspectos positivos de la gestión del proyecto hay un desarrollo de habilidades investigativas y expositivas en el estudiantado y obtención de destrezas y conocimientos, resultados de los objetivos planificados por la gestión.

Basados en las conclusiones se ofrecen recomendaciones, con el fin de mejorar la gestión del Proyecto en los distintos centros educativos analizados. Por consiguiente se considera oportuno que en dicho centros estudiados se dé una revaloración de su comunicación. Además, una integración de todos los miembros de los centros educativos. También hay que realizar una retroalimentación entre docentes y gestores; y una evaluación constante e integradora que garantice la calidad. Así como también una mayor relación entre la institución educativa con las comunidades.

Teniendo en cuenta las conclusiones y recomendaciones planteadas partiendo del análisis de la información obtenida, se considera finalmente que el administrador de la educación debe ser un

Licencia Creative Commons 
sujeto integrador y mediador. Para ello debe posicionarse como la autoridad y empoderarse de los procesos. Además, debe articular la estructura educativa por medio de un liderazgo transformacional.

\section{Referencias}

Botero,C.A.(2009).Cincotendenciasdelagestióneducativa.RevistalberoamericanadeEducación,49(2), 1-11.(Politécnico Colombiano Jaime Isaza Cadavid) Colombia: Organización de Estados Iberoamericanos para la Educación, la Ciencia y la Cultura (OEI). Recuperado de: http://www.rieoei.org/deloslectores/2811Botero.pdf

Chacón, M. L. (2002). El director como organizador y gestor de los procesos educativos. (Tesis de Doctorado, Universidad de Costa Rica). Ciudad Universitaria Rodrigo Facio, San José, Costa Rica.

Da Silva, R. (2002). Teorías de la administración. México: Thomson Learning. Recuperado de: http://books.google. co.cr/books?id=tPH5caAXYgcC\&dq=mary+parker+follet $\mathrm{t}+$ coordinaci\%C3\%B3n\&hl=es\&s ource $=$ gbs navlinks $s$

Díaz, W. (2005). La planificación institucional en la gestión directiva en las escuelas técnicas del circuito 03 de la Dirección Regional de Desamparados. (Tesis de Maestría, Universidad de Costa Rica). Ciudad Universitaria Rodrigo Facio, San José, Costa Rica.

D’ Agostino, G. (1995). Aspectos teóricos de la evaluación educacional. Una orientación para su puesta en práctica en la enseñanza primaria. San José, Costa Rica: EUNED.

Garbanzo, G. M. y Orozco, V. H. (2007). Desafíos del sistema educativo costarricense: un nuevo paradigma de la administración de la educación. Revista Educación, 31 (2), 95-110. Recuperado de: http:// latindex.ucr.ac.cr/index.php/educacion/article/viewFile/1246/1309

García, J. R. (2009). La gestión escolar como medio para lograr la calidad en instituciones públicas de educación primaria en Ensenada, Baja California. (Tesis de Maestría, Instituto de Investigación y Desarrollo Educativo [IIDE]) México. Recuperado de: http://iide.ens.uabc.mx/blogs/mce/files/2011/03/TesisJihanGarc\%C3\%ADa-Poyato.pdf

González, L. (2005). La evaluación en la gestión de proyectos y programas de desarrollo. Una propuesta integradora en agentes, modelos y herramientas. España: Vitoria-Gasteiz: Eusko Jaurlaritzaren Argitalpen Zerbitzu Nagusia = Servicio Central de Publicaciones del Gobierno Vasco. Recuperado de: http://biblioteca.hegoa.ehu. 


\section{es/system/ebooks/14809/original/La evaluacion en la gestion de proyectos.pdf}

Hernández, R., Fernández, C. y Baptista, P. (2006). Metodología de la investigación. México: McGraw-Hill Interamericana.

Koontz, H., Weihrich, H. y Cannice, M. (2008). Administración: una perspectiva global y empresarial. México: Mc Graw Hill.

Newstrom, J. W. (Ed.). (2007). Dirección: gestión para lograr resultados. México: McGraw-Hill Interamericana.

Martins, F., Cammaroto, A. J., Neris, L. M., y Canelón, E. (2009). Liderazgo transformacional y gestión educativa en contextos descentralizados. Revista Actualidades Investigativas en Educación, 9 (2), 1-27. Recuperado de: http://revista.inie.ucr.ac.cr/uploads/tx magazine/lide.pdf

McMillan, J. H. y Schumacher, S. (2005). Investigación educativa. Madrid: Pearson Educación.

Ministerio de Educación Pública. (2009). Proyecto de Ética, Estética y Ciudadanía: programas de estudio Educación Cívica. San José, Costa Rica: Autor.

Mora, C. (2011). Labor del coordinador académico en la gestión del currículo en las organizaciones educativas de secundaria pública. Revista Gestión de la Educación, 1 (2), 1-34. Recuperado de: http://revistadigital.eae.fcs.ucr.ac.cr/images/stories/EDICION2/ docs/01Laborcoordinadoracademico-CarolinaMora.pdf

Mora, G. A. (1998). Proyecto Curso de capacitación para el mejoramiento del proceso de supervisión y evaluación curricular de la unidad pedagógica Dr. Rafael Ángel calderón Guardia. (Memoria de práctica dirigida de Licenciatura, Universidad de Costa Rica). Ciudad Universitaria Rodrigo Facio, San José, Costa Rica.

Naranjo, J. C. (2012). Aporte del programa ética, estética y ciudadanía en el fortalecimiento de los derechos humanos de la adolescencia. (Tesis de Maestría, Universidad de Costa Rica). Ciudad Universitaria Rodrigo Facio, San José, Costa Rica. 
Solera, M. (2011). Análisis de los procesos de gestión del proyecto extracurricular Banda Instrumental Escuela Riojalandia y su impacto en el entorno educativo. (Tesis de Maestría, Universidad de Costa Rica. Sede del Pacífico, Puntarenas, Costa Rica.

Ricart, J. E. y Rodríguez, M. A. (2004). Coordinación de los sistemas de gestión de calidad, medio ambiente y salud laboral. Parte I. España: Ediciones Deusto - Planeta de Agostini Profesional y Formación S.L. Recuperado de: http://site.ebrary.com/id/10063212

Reyes, A. (2005). Administración de empresas. Teoría y práctica. México: Editorial Limusa.

Rodríguez, J. (2003). Introducción a la administración con enfoque de sistemas. México: THOMSON. Recuperado de: http://books.google.es/books?id=kr5rp22vgH0C\&pg=PA108\&dq=Introduc ci \%C3\%B3n+a+la+Administraci\%C3\%B3n+con+Enfoque+de+Sistemas\&hl=e s\&sa=X\&ei=X O6yUN73|4Wm8gTVx4HIAw\&ved=0CDMQ6wEwAA

Vargas, I. (2008). Análisis de cinco desafíos en el ejercicio de la administración educativa. Revista Electrónica Actualidades Investigativas en Educación, 8 (1), 1-15. Recuperado de: http://revista. inie.ucr.ac.cr/uploads/tx magazine/desafios.pdf

Venegas, P. (2011). Gestión de la educación basada en competencias: elementos para su interpretación en el contexto de la Administración de la Educación. Revista Gestión de la Educación, 1(1), 1-27. Recuperado de: http://www.latindex.ucr.ac.cr/gestion-1-1/gestion-1-1-03. pdf

Zambrano, B. y Marval, E. (2008). Acción directiva: un enfoque centrado en competencias. Revista Venezolana de Gerencia, 13 (44), 616-636. Recuperado de: http://www.redalyc.org/articulo. oa?id=29004407 